\title{
Mechanism of Sulfate Formation During the Roasting Of
}

\section{Cuprous Sulfide}

\author{
by C. L. McCabe and J. A. Morgan
}

$I^{\mathrm{N}}$ $\mathrm{N}$ the art of roasting sulfides it is well known that the lower the temperature and the higher the pressure of $\mathrm{SO}_{3}$, the larger will be the amount of sulfate present in the product. However, the mechanism of sulfate formation is not generally understood. The following experiment* demonstrates in a direct way

*Peretti ${ }^{1}$ has reported observations similar to those in this note.

that, in the roasting of $\mathrm{Cu}_{2} \mathrm{~S}$, the sulfate forms from the reaction of $\mathrm{Cu}_{2} \mathrm{O}$, formed by the oxidation of $\mathrm{Cu}_{2} \mathrm{~S}$, with gaseous $\mathrm{SO}_{2}$ (or $\mathrm{SO}_{3}$ ) and $\mathrm{O}_{2}$. Thus, the sulfate does not form at the sulfide surface. The reaction at the sulfide surface is the same whether or not sulfate is formed. Using an indirect method, Ong, Fassell, and Wadsworth ${ }^{2}$ infer that sulfate forms after oxidation, during the roasting of sphalerite, agreeing with the observations of this paper. The method presented here of demonstrating that sulfate forms after formation of $\mathrm{Cu}_{2} \mathrm{O}$ is to roast a sample of $\mathrm{Cu}_{2} \mathrm{~S}$ and then to locate and identify the phases formed. ${ }^{1}$

A solid cube of cuprous sulfide, made by melting Fisher reagent grade $\mathrm{Cu}_{2} \mathrm{~S}$ powder and measuring about $1.5 \mathrm{~cm}$ on edge, was placed on a Nichrome wire grid suspended over the top of an Alundum combustion boat. The assembly was placed in a tube furnace at $600^{\circ} \mathrm{C}$ and oxygen gas, flowing at 0.60 liters per min, was passed around the specimen for $24 \mathrm{hr}$. The furnace tube diameter was $1.5 \mathrm{in}$. The partially roasted sample was removed from the furnace and impregnated with resin No. BR 0014, obtained from the Palmer Products Co., and the impregnated sample was then mounted in Lucite. A cross section was obtained by grinding and the surface was prepared by the following steps: 1) grinding-60 grit, 3M disk, dry; 2) preliminary polishing -60 through 600 grit, 3M disk, dry; 3) polishing$8 \mu$ diamond putty, silk cloth; and 4) final polishing -levigated magnesia in isopropyl alcohol, Selvyt cloth.

The color micrograph of the polished surface is shown in Fig. 1. The layers present in the micrograph are given along the side.

The compositions of the various layers were established by Debye-Scherrer patterns. From this evidence the following sequence of reactions which occur in the roasting of $\mathrm{Cu}_{2} \mathrm{~S}$ is inferred:

1) The oxidation of $\mathrm{Cu}_{2} \mathrm{~S}$ occurs with oxygen which has been transported through the oxidesulfate layer by either gaseous or solid state diffu-

C. L. McCABE, Associate Member AIME, and J. A. MORGAN are Assistant Professor of Metallurgical Engineering and Junior Research Metallurgical Engineer, Metals Research Laboratory, respectively, Carnegie Institute of Technology, Pittsburgh.

TN 291D. Manuscript, June 13, 1955.

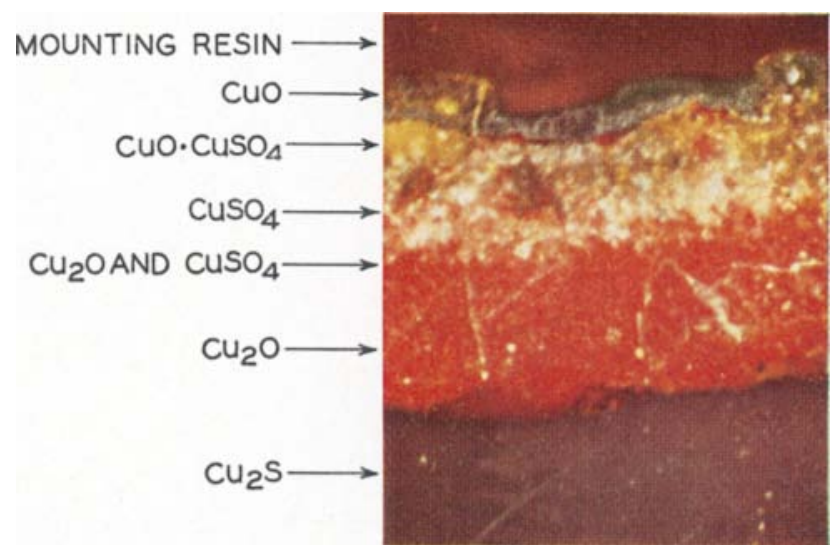

Fig. 1-Color micrograph shows outer oxide and sulfate layers formed during the roasting of $\mathrm{Cu}_{2} \mathrm{~S}$. Unetched specimen was photographed under polarized light. X100. Area reduced approximately 10 pet for reproduction.

sion. The products of this reaction at the $\mathrm{Cu}_{2} \mathrm{~S}$ surface are $\mathrm{Cu}_{2} \mathrm{O}$ and $\mathrm{SO}_{2}$.

2) The $\mathrm{SO}_{2}$ diffuses out through the pores in the $\mathrm{Cu}_{2} \mathrm{O}$ and finally reaches a position in the $\mathrm{Cu}_{2} \mathrm{O}$ where the oxygen pressure and the $\mathrm{SO}_{2}$ pressure have values such that the thermodynamic conditions for the formation of $\mathrm{CuSO}_{4}$ are fulfilled. Then, the mixture of $\mathrm{SO}_{2}, \mathrm{SO}_{3}$, and oxygen reacts with the $\mathrm{Cu}_{2} \mathrm{O}$ to form $\mathrm{CuSO}_{4}$.

3) The $\mathrm{CuSO}_{4}$ decomposes by the evolution of $\mathrm{SO}_{3}$, or $\mathrm{SO}_{2}$ and $\mathrm{O}_{2}$, to form the basic sulfate. This is reasonable, since the $\mathrm{SO}_{3}$ gradient will decrease toward the oxygen gas phase from the $\mathrm{CuSO}_{4}$ layer.

4) For this same reason the basic sulfate will decompose to form $\mathrm{CuO}$.

The above sequence of events is based on the assumption that diffusion through the oxide and sulfate layers, rather than the reaction at the sulfideoxide interface, is rate-determining. This assumption is supported by the observation that these oxide and sulfate layers combined are almost nonpermeable to the flow of gases through them.

\section{Acknowledgments}

This research was supported by the U. S. Air Force, through the Office of Scientific Research of the Air Research and Development Command. The authors wish to acknowledge the helpful suggestions of Ralph Wells of the Applied Research and Development Laboratory, U. S. Steel Corp.

\section{References}

1 E. A. Peretti: A New Method for Studying the Mechanism of Roasting Reactions. Discussions Faraday Soc. (1948) 4, p. 174 2 J. N. Ong, Jr., M. E. Wadsworth, and W. M. Fassell, Jr.; Kinetic Study of the Oxidation of Sphalerite. Trans. AIME (1956) 206, pp.
257-263; Journal OF Metals (February 1956). 